\title{
Conformationally restricted nucleotides as a probe of structure-function relationships in RNA
}

\author{
KRISTINE R. JULIEN, ${ }^{1}$ MINAKO SUMITA, ${ }^{1}$ PO-HAN CHEN, ${ }^{2}$ ITE A. LAIRD-OFFRINGA, ${ }^{2,3}$ \\ and CHARLES G. HOOGSTRATEN ${ }^{1}$ \\ ${ }^{1}$ Department of Biochemistry and Molecular Biology, Michigan State University, East Lansing, Michigan 48824, USA \\ ${ }^{2}$ Department of Biochemistry and Molecular Biology, University of Southern California, Los Angeles, California 90089, USA \\ ${ }^{3}$ Department of Surgery, Keck School of Medicine, University of Southern California, Los Angeles, California 90089, USA
}

\begin{abstract}
We introduce the use of commercially available locked nucleic acids (LNAs) as a functional probe in RNA. LNA nucleotides contain a covalent linkage that restricts the pseudorotation phase of the ribose to C 3 '-endo (A-form). Introduction of an LNA at a single site thus allows the role of ribose structure and dynamics in RNA function to be assessed. We apply LNA probing at multiple sites to analyze self-cleavage in the lead-dependent ribozyme (leadzyme), thermodynamic stability in the UUCG tetraloop, and the kinetics of recognition of U1A protein by U1 snRNA hairpin II. In the leadzyme, locking a single guanosine residue into the $\mathrm{C}^{\prime}$-endo pucker increases the catalytic rate by a factor of 20 , despite the fact that X-ray crystallographic and NMR structures of the leadzyme ground state reported a C2'-endo conformation at this site. These results strongly suggest that a conformational change at this position is critical for catalytic function. Functional insights obtained in all three systems demonstrate the highly general applicability of LNA probing in analysis of the role of ribose orientation in RNA structure, dynamics, and function.
\end{abstract}

Keywords: locked nucleic acid; lead-dependent ribozyme; RNA-protein recognition; sugar pucker; thermodynamics

\section{INTRODUCTION}

As with all biological macromolecules, the function of RNA is dependent on its three-dimensional structure. The conformation of a nucleotide residue within an RNA or DNA molecule is defined by the six backbone torsion angles $\alpha, \beta$, $\gamma, \delta, \varepsilon$, and $\zeta$, the glycosidic torsion angle $\chi$, and the furanose sugar pucker phase $\mathrm{P}$ and amplitude $\Phi$ (Saenger 1984). The pucker phase $\mathrm{P}$ varies between $0^{\circ}$ and $360^{\circ}$ and defines the nucleotide's position on the pseudorotation cycle for the five-membered ribose ring (Altona and Sundaralingam 1972). The sugar pucker phase is generally confined to two distinct regions of the $360^{\circ}$ pseudorotation cycle, C3'-endo ("North"), roughly corresponding to a range of $0^{\circ}$ to $36^{\circ}$ and observed in A-form helices, and $\mathrm{C} 2^{\prime}$ endo ("South") corresponding to a range of $144^{\circ}$ to $180^{\circ}$ and observed in B-form helices (Fig. 1; Altona and Sundaralingam 1972; Saenger 1984). Nonhelical regions

Reprint requests to: Charles G. Hoogstraten, Department of Biochemistry and Molecular Biology, Michigan State University, East Lansing, MI 48824, USA; e-mail: hoogstr3@msu.edu; fax: (517) 353-9334.

Article published online ahead of print. Article and publication date are at http://www.rnajournal.org/cgi/doi/10.1261/rna.866408. may contain nucleotides of either conformation or display an equilibrium between the two states.

Conformational flexibility in RNA is essential for processes including protein-RNA recognition and RNA catalysis (Perez-Canadillas and Varani 2001; Treiber and Williamson 2001; Fedor and Williamson 2005). However, it often proves difficult to probe directly the functional significance of a particular RNA conformational change or dynamic region. Our group has recently introduced a specific isotope-labeling scheme that allows the facile NMR analysis of dynamics within the ribose ring of RNA, which are hypothesized to most often represent $\mathrm{C}^{\prime}$ '-endo/C2' endo interconversions (Johnson et al. 2006). Preliminary application of this method to the lead-dependent ribozyme, or leadzyme, has shown a variety of dynamic features at ribose rings within the active site (M. Sumita, J.E. Johnson, and C.G. Hoogstraten, unpubl.; data not shown). Thus, we are interested in developing methods to assess the functional significance of $\mathrm{C} 3{ }^{\prime}$-endo/C2' -endo conformational changes. Historically, such probing has been attempted by taking advantage of conformational preferences of nucleotides with various substitutions at the $2^{\prime}$-carbon, but these efforts have been handicapped by the relatively modest magnitude of such preferences, representing a maximum of $\sim 0.8$ 


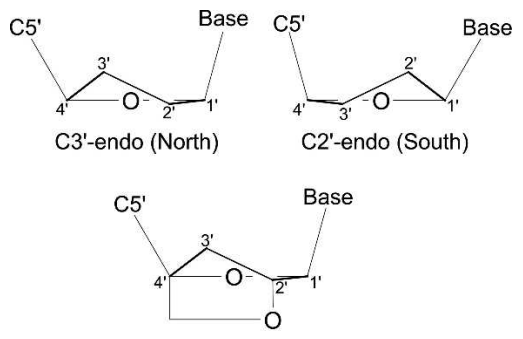

Locked Nucleic Acid (LNA)

FIGURE 1. Conformationally locked nucleotides. (Top) Edge-on views of $\mathrm{C}^{\prime}$ '-endo and $\mathrm{C}^{\prime}$-endo nucleic acid ribose pucker conformations. (Bottom) The introduction of a covalent linkage between $\mathrm{C}^{\prime}$ and $\mathrm{C}^{\prime}{ }^{\prime}$ in locked nucleic acid (LNA) nucleotides. This linkage is geometrically incompatible with the $\mathrm{C} 2$ '-endo pucker and thus locks the nucleotide into the $\mathrm{C} 3$ '-endo conformation. Upper panel, structure redrawn from Altona and Sundaralingam (1972).

$\mathrm{kcal} / \mathrm{mol}$ at $298 \mathrm{~K}$ for the most commonly used nucleotides (Uesugi et al. 1979; Guschlbauer and Jankowski 1980).

A recently introduced nucleotide modification of great interest for therapeutic and diagnostic applications of oligonucleotides is locked nucleic acid (LNA), which features a methylene linkage between the $2^{\prime}$-oxygen and $4^{\prime}$ carbon to completely restrict the nucleotide to the $3^{\prime}$-endo conformation (Fig. 1; Koshkin et al. 1998a,b; Obika et al. 1998). The properties and applications of LNAs and related molecules have been reviewed (Braasch and Corey 2001; Vester and Wengel 2004; Karkare and Bhatnagar 2006; Kaur et al. 2007). In brief, by significantly reducing the entropy cost of the transition from the single-stranded state to an A-form helix, even a small number of LNA nucleotides introduced into an oligomer can dramatically increase the stability of RNA double helices, DNA-RNA hybrids, and triple helices via preorganization effects (Kool 1997; Kierzek et al. 2005). Extensive applications of LNA-containing oligonucleotides to antisense, siRNA, and related technologies have been reported (Karkare and Bhatnagar 2006).

In this article, we report the novel application of LNAs as probes of functional relationships in folded RNA molecules. We measure the effects of individual substituted LNA nucleotides on catalytic function in the leadzyme, the folding thermodynamics of the stable UUCG tetraloop, and the kinetics of recognition by the spliceosomal U1A protein of its target sequence in the U1 small nuclear RNA (snRNA). The results give precise insight into site-specific conformational and energetic properties in the probed systems.

\section{RESULTS}

\section{Conformational restriction and RNA catalysis}

The small, catalytic lead-dependent ribozyme consists of an A-form RNA duplex with an asymmetric internal loop that contains the active site for self-cleavage (Fig. 2). Catalysis occurs in the presence of lead ions, which promote a two- step cleavage reaction of the phosphodiester linkage between residues C6 and G7 (Pan and Uhlenbeck 1992; Pan et al. 1994). A unique feature of this ribozyme is its strong selectivity for divalent lead compared to all other metal ions tested. Thus, mechanistic analysis provides the opportunity for insight into the construction of a highly specific functional metal-ion site by RNA. Although the structure of the leadzyme has been analyzed by both NMR (Hoogstraten et al. 1998; Legault et al. 1998) and X-ray crystallography (Wedekind and McKay 1999, 2003), the resulting structures have neither displayed the in-line attack geometry necessary for self-cleavage nor provided a satisfactory explanation of the biochemical data for the system (Pan et al. 1994; Chartrand et al. 1997; Legault et al. 1998). These observations can be explained if the active-site internal loop of the leadzyme must undergo a transient fluctuation from the observed ground-state structure ES to an active conformation $\mathrm{ES}^{*}$ prior to the chemical step of the reaction (Fig. 2, bottom). Thus, determining the features of the conformational change that creates $\mathrm{ES}^{*}$ is a critical issue in delimiting the mechanism and metal specificity of this model ribozyme. In the current study, we analyzed the cleavage kinetics of three leadzyme constructs, each containing a
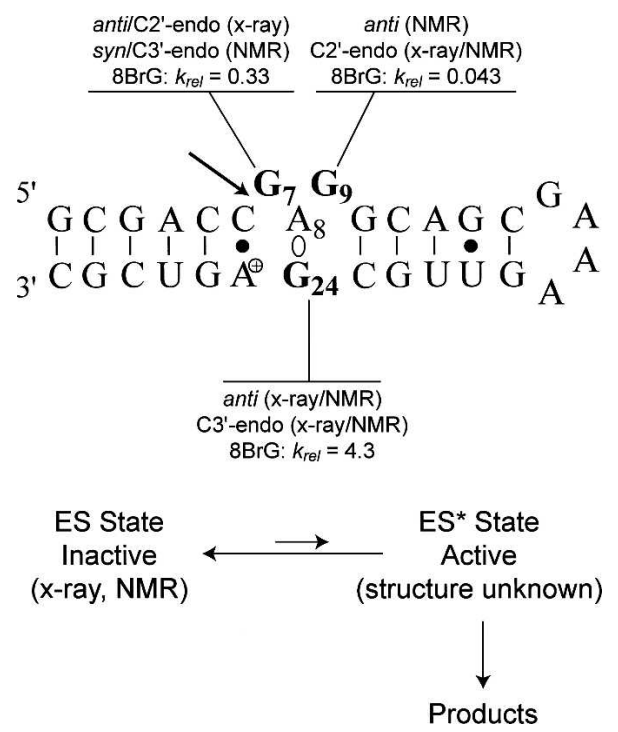

FIGURE 2. The lead-dependent ribozyme. (Top) Secondary structure of the leadzyme construct used in this work (LZ2), including the protonated noncanonical C6-A25 wobble base pair and the dynamic A8-G24 interaction. Sugar pucker and glycosidic angle parameters from X-ray (Wedekind and McKay 2003) and NMR (Hoogstraten et al. 1998) structures, along with the self-cleavage rates of $8 \mathrm{BrG}$ substitutions relative to wild type $\left(k_{\text {rel }}\right)$ (Yajima et al. 2007), are indicated for nucleotides G7, G9, and G24. For G7, the crystallographic and NMR structures differ for both sugar pucker and glycosidic angle. For G9, the glycosidic angle takes on multiple conformations in the crystal structure due to packing constraints. The site of lead-dependent self-cleavage is indicated with an arrow. (Bottom) Sketch of the postulated transition from the ground-state, inactive form of the leadzyme (ES) to a low-population active conformation of unknown structure $\left(\mathrm{ES}^{\star}\right)$. 
single LNA-G substitution at G7, G9, or G24. Previously reported measurements of $2^{\prime}$-deoxy variants at these positions yielded $k_{r e l}\left(2^{\prime}-\mathrm{H}\right)$ values varying from 0.20 for dG24 to 0.76 for dG9 (Table 1; Chartrand et al. 1997). Thus, the loss of the $2^{\prime}-\mathrm{OH}$ hydrogen bond donor at these positions leads to a modest to moderate loss of function, providing an important control for LNA substitutions.

A unimolecular leadzyme construct, termed LZ2, was used for all LNA kinetics experiments (Fig. 2). Representative time courses of cleavage at $\mathrm{pH} 7.0$ and $50 \mu \mathrm{M} \mathrm{Pb}^{2+}$ are shown in Figure 3, and measured values of $k_{\mathrm{obs}}$ under these conditions are reported in Table 1 . The self-cleavage rate of wild-type LZ2 was found to be $0.93 \pm 0.15 \mathrm{~min}^{-1}$, in agreement with the initial results of the Uhlenbeck group (Pan and Uhlenbeck 1992; Pan et al. 1994). Cleavage rates in the wild-type leadzyme are generally seen to increase with increasing concentration of $\mathrm{Pb}^{2+}$ to a maximum in the neighborhood of $1 \mathrm{~min}^{-1}$ and then decrease as $\left[\mathrm{Pb}^{2+}\right]$ is further increased due to the formation of lead polyhydroxide species at the $\mathrm{pH}$ used (Pan et al. 1994; Yajima et al. 2007). Consistent with these earlier observations, we find a maximum rate of leadzyme activity at $\sim 50 \mu \mathrm{M} \mathrm{Pb}^{2+}$ for all variants (Fig. 4). The decline in activity at $>50 \mu \mathrm{M} \mathrm{Pb}^{2+}$ precludes an analysis of saturation (Michaelis-Menten) kinetics, but $k_{\mathrm{obs}}$ values at $50 \mu \mathrm{M} \mathrm{Pb}^{2+}$ report well on the initial slopes of the $k_{\mathrm{obs}}$ versus $\left[\mathrm{Pb}^{2+}\right]$ curves (i.e., $k_{\text {cat }} / K_{M}\left[\mathrm{~Pb}^{2+}\right]$ ) (Fig. 4 , inset).

It is apparent from the data that conformational restriction at site 7 has only modest effects on catalysis, consistent with the varying conformations observed in structures for this nucleotide (Fig. 2; Table 1) and the relative insensitivity of this site to nucleotide base modifications (Pan et al. 1994; Chartrand et al. 1997; Yajima et al. 2007). By contrast, LNA modification at G24 induces a moderate loss of reactivity, decreasing self-cleavage by $>15$-fold relative to wild type. This observation is unexpected given that a C3' endo conformation is consistently observed at this position (22 of 25 calculated NMR structures and all crystallographic structures). Although the attenuation of activity is modest relative to the fivefold decrease upon $2^{\prime}$-deoxy substitution (Chartrand et al. 1997), this observation may suggest that the ability to escape the A-form ground state at this site, an ability suppressed by the LNA motif, is advantageous for catalysis. This possibility is strengthened by the observation that substitution at this position with 8bromoguanosine $(8 \mathrm{BrG})$, which strongly disfavors the anti glycosidic conformation and concomitantly prefers a $\mathrm{C} 2{ }^{\prime}$ endo pucker, results in a fourfold enhancement of catalytic rate (Yajima et al. 2007). Taken together, these results suggest the existence of a conformational change at this position that favors self-cleavage.
At site G9, NMR and crystallographic structures agree on a $\mathrm{C} 2$ ' -endo conformation in the ground state. ${ }^{1}$ Nevertheless, restriction of $\mathrm{G} 9$ to the $\mathrm{C} 3{ }^{\prime}$-endo conformation using LNA modification leads to a dramatic increase in the measured rate of self-cleavage to $19.1 \mathrm{~min}^{-1}$, an increase over the wild-type rate of more than 20-fold. (Due to the limitations of kinetic measurements using manual pipetting, this value is best considered as a lower bound on the rate of self-cleavage; our confidence in its accuracy, however, is increased by the linearity of the $k_{\text {obs }}$ versus $\left[\mathrm{Pb}^{2+}\right]$ curve for this variant between $10 \mu \mathrm{M}$ and $50 \mu \mathrm{M} \mathrm{Pb}^{2+}$; Fig. 4, inset). To our knowledge, this value is the highest catalytic rate observed in any leadzyme variant under any conditions. The relevance of the observed reaction to the mechanism of the wild-type leadzyme was verified by the absence of measurable activity in $10 \mathrm{mM}$ $\mathrm{Mg}^{2+}$ in the absence of $\mathrm{Pb}^{2+}$ (data not shown). The rate versus $\left[\mathrm{Pb}^{2+}\right]$ plots in Figure 4 reemphasize the dramatic increase in cleavage rate for the LNA-G9 variant under all conditions tested. Significantly, this increase in rate was achieved by preventing the formation of the ground-state structure determined experimentally by two different techniques. This result implies that an inversion of the pseudorotation state of G9 from $\mathrm{C} 2{ }^{\prime}$-endo to $\mathrm{C} 3{ }^{\prime}$-endo is an energetically significant factor in the conformational change postulated to generate the active state of the leadzyme (Fig. 2). We propose that locking this ribose in the active ( $\mathrm{C}^{\prime}$-endo) conformation greatly increases the catalytic rate by substantially increasing the population of the active conformer. In combination with previous results (see Discussion), the LNA substitution analysis reported here strongly supports and further refines the model that a dramatic rearrangement of active-site structure in the leadzyme is necessary to generate a catalytically competent conformation.

\footnotetext{
${ }^{1}$ It should be noted, however, that Boisbouvier et al. (2000), in an initial assessment of the potential for cross-correlated NMR relaxation techniques to determine sugar pucker conformation, found these parameters for G9 to cluster with those in $\mathrm{C}^{\prime}$-endo nucleotides.
} 


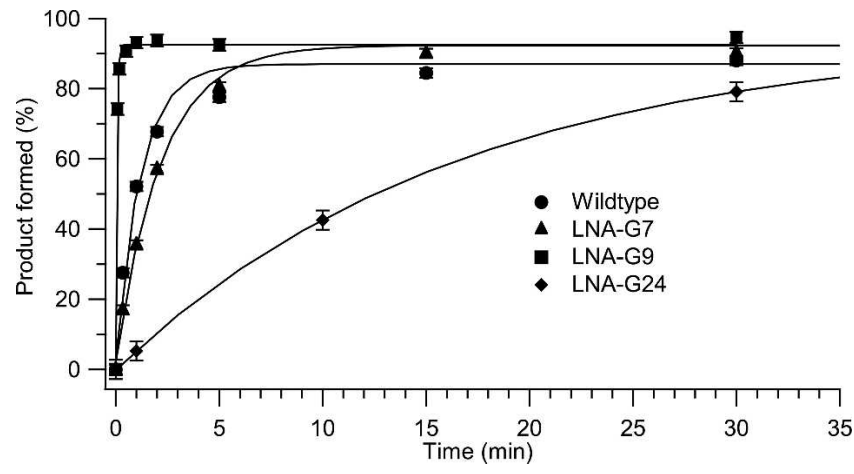

FIGURE 3. Reaction profiles for leadzyme self-cleavage. Progress curves for wild type (Fig. 2) and LNA-G variants in $15 \mathrm{mM}$ MOPS $(\mathrm{pH} 7.0)$ and $50 \mu \mathrm{M} \mathrm{Pb}^{2+}$ are shown. Data points were calculated as the average of two runs with error bars representing the difference between duplicate determinations averaged over a single time course.

\section{Conformational restriction and tetraloop folding thermodynamics}

The UUCG tetraloop (Fig. 5) is a well-studied RNA hairpin with unusually high stability that has been the subject of detailed calculational and thermodynamic studies (Groebe and Uhlenbeck 1988; Tuerk et al. 1988; Sakata et al. 1990; Antao and Tinoco 1992; Miller and Kollman 1997; Williams and Hall 1999, 2000; Williams et al. 2001; Ma et al. 2006). The well-defined molecular structure has been determined by both NMR (Cheong et al. 1990; Varani et al. 1991) and X-ray crystallography (Ennifar et al. 2000). In this tetraloop, U5 and G8 have C3'-endo sugar puckers and U6 and C7 are observed in $\mathrm{C}^{\prime}{ }^{\prime}$-endo conformations. Structural stabilization is provided by hydrogen bonding interactions between U5 (anti) and G8 (syn), as well as between C7 and the U6 phosphate group. $\mathrm{C} 2$ '-endo nucleotides can span a longer backbone distance (Saenger 1984) and thus allow the formation of a loop structure from the two nucleotides spanning the U5G8 base pair. Preorganization of the syn conformation at site G8 via $8 \mathrm{BrG}$ substitution has been observed to enhance thermodynamic stability relative to the unmodified hairpin (Proctor et al. 2004).

In order to investigate the thermodynamic importance of sugar conformation in the structured UUCG tetraloop, we introduced LNA nucleotides at the U6 and G8 positions, which are observed to have $\mathrm{C}^{2}$-endo and $\mathrm{C} 3{ }^{\prime}$-endo conformations, respectively. Because the LNA-uridine phosphoramidite is not commercially available, LNAthymidine was used for modification at U6. Thymidine was used as a control for the effects of the loss of the 2'-hydroxyl. At site 8, 2'-O-methyl guanosine $(\mathrm{Gm})$ was used as a parallel control for the LNAguanosine modification.

UV melting curves of UUCG tetraloop analogs were performed at $\mathrm{pH} 7.0$ in low salt buffer $\left(10 \mathrm{mM} \mathrm{Na}^{+}\right)$to favor the formation of the hairpin form over an RNA duplex. The two-state unfolding transitions occurred between $50^{\circ} \mathrm{C}$ and $85^{\circ} \mathrm{C}$ and were independent of RNA concentration between $5 \mu \mathrm{M}$ and $100 \mu \mathrm{M}$, demonstrating unimolecular folding of the hairpin structure. Nondenaturing polyacrylamide gel electrophoresis did not reveal any evidence for duplex formation for any of the UUCG tetraloop analogs (data not shown). The curves were well fit by a two-state model in terms of melting temperature $\left(T_{m}\right), \Delta H^{\circ}, \Delta S^{\circ}$, and $\Delta G^{\circ}{ }_{37}$. Thermodynamic parameters obtained from the resulting fits are listed in Table 2.

For nucleotide U6 (U $\underline{U} C G$ ), the uridine base is exterior to the loop and has no important interactions with other groups (Cheong et al. 1990; Ennifar et al. 2000). At this site, the $\Delta G^{\circ}{ }_{37}$ values for UUCG (wild type) and UTCG are identical within error, consistent with the uridine to thymidine modification (including the deletion of the $2^{\prime}$ hydroxyl) having no significant effect on hairpin stability. Our data for UTCG are very similar to previously reported results for a deoxyuridine substitution at this position (Williams and Hall 1999; Williams et al. 2001). The 2'hydroxyl at position 6 clearly plays no important role in the structure or stability of the tetraloop.

In contrast, an tetraloop with an LNA substitution at position 6 to yield $\mathrm{U}(\mathrm{LNA}-\mathrm{T}) \mathrm{CG}$ is $\sim 2 \mathrm{kcal} / \mathrm{mol}$ less stable than the UTCG analog at $37^{\circ} \mathrm{C}$, with a decrease in $T_{m}$ of almost $10^{\circ} \mathrm{C}$. In structures of the wild-type tetraloop, this residue has a $\mathrm{C} 2^{\prime}$-endo conformation, accounting for the

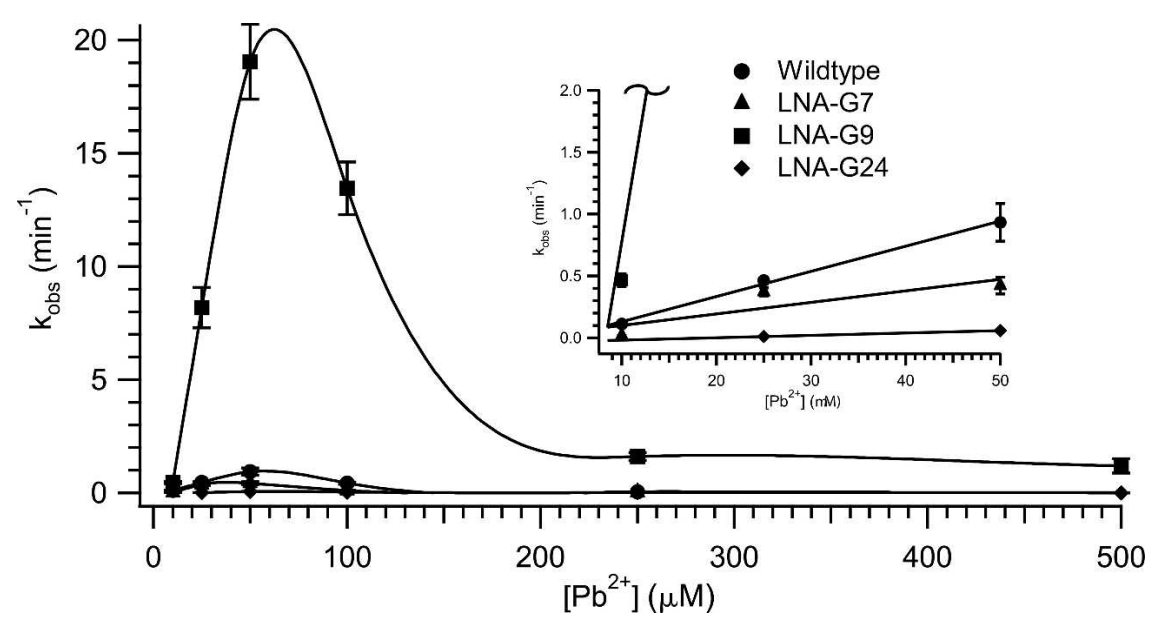

FIGURE 4. Metal dependence of leadzyme analog activity. Self-cleavage rates for LZ2 wild type and LNA substitutions as a function of added $\left[\mathrm{Pb}^{2+}\right]$. Curves are cubic spline fits to guide the eye. (Inset) Expansion of the data with linear interpolation for $\left[\mathrm{Pb}^{2+}\right]$ through $50 \mu \mathrm{M}$. At this scale, the fit for LNA-G9 rapidly moves off the top of the plot. 

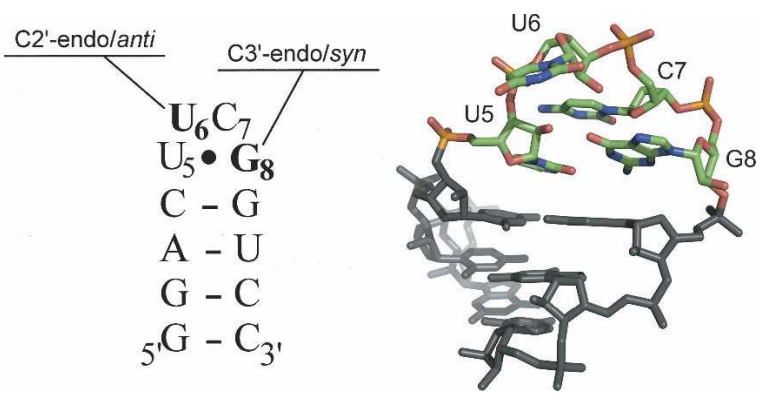

FIGURE 5. The UUCG tetraloop. (Left) The secondary structure of the construct used in this work is shown, with nucleotides individually substituted with LNA drawn in bold and labeled with pucker phase and glycosidic conformation. (Right) X-ray crystallographic conformation, pdb code 1F7Y (Ennifar et al. 2000). Three-dimensional figure drawn with PyMOL (Delano 2002).

drastic decline in tetraloop stability when a C3'-endo conformation is enforced. Additionally, the enthalpy change decreases in magnitude from $-44.1 \mathrm{kcal} / \mathrm{mol}$ (UTCG) to $-32.0 \mathrm{kcal} / \mathrm{mol}$ (U[LNA-T]CG), suggesting that the base pair between U5 and G8 may be disrupted due to the rigid C3'-endo sugar pucker orientation of LNA-T6. This observation is consistent with an NMR study of a UUCG tetraloop with a modification at position 6 to $2^{\prime}$-deoxy2 '-fluoro-uridine, which prefers a $\mathrm{C}^{\prime}$ '-endo conformation (Guschlbauer and Jankowski 1980). The 2'-fluoro substituted tetraloop displayed broadening and loss of intensity of the loop imino proton resonances, suggesting disruption of hydrogen bonding and a more dynamic loop structure (Williams et al. 2001). Thus, the results of LNA substitution at position 6 are consistent with the known structure and properties of the tetraloop and indicate that the sugar pucker for this nucleotide is a critical determinant of tetraloop stability.

Residue G8 has a C3'-endo sugar orientation and no close hydrogen-bonding contacts involving the 2'-hydroxyl group. Nevertheless, a deoxy substitution at this position showed a moderate decrease in loop stability $\left(\Delta T_{m}=\right.$ $-4.1^{\circ} \mathrm{C}, \Delta \Delta G^{\circ}=+0.5 \mathrm{kcal} / \mathrm{mol}$ at $55^{\circ} \mathrm{C}$ ) (Williams et al. 2001). Ennifar et al. (2000) suggested that the thermodynamics at this position were dominated by a requirement for a $\mathrm{C}^{\prime}$-endo ribose. Since a 2'-O-methyl nucleotide slightly favors the $\mathrm{C} 3^{\prime}$-endo ribose, this model would predict a negligible effect or slightly increased stability for $\mathrm{Gm}$ at position 8 , and a potential increase in stability for LNA-8 due to preorganization of the tetraloop structure. In contrast, the present data show a substantial decrease in loop stability upon 2'-O-methyl substitution that is still more severe in the LNA modification. These data suggest that, rather than the thermodynamics of G8 substitutions being driven by ribose conformational preferences, the $2^{\prime}$-hydroxyl at position 8 plays a heretofore unrecognized role in the tetraloop structure. Interestingly, a molecular dynamics simulation study of the tetraloop showed the development of a hydrogen bond between the 2'-OH at G8 and the phosphate backbone (Miller and Kollman 1997). Therefore, the destabilizing effect of modified RNAs at the G8 position may in fact be attributable to the deletion of the $2^{\prime}-\mathrm{OH}$ hydrogen bond donor. In any case, our results at this site underline the importance of analyzing 2 '-deoxy and/or 2'$O$-methyl nucleotides in parallel with an LNA substitution to control for any effects of chemical modification at the $2^{\prime}$ position that are independent of ribose conformation.

\section{Conformational restriction and RNA-protein recognition}

The interaction between the N-terminal RNA recognition motif (RRM) of the A protein of the U1 small ribonucleoprotein particle (U1A) and its RNA target in the U1 snRNA, U1 hairpin II (U1hpII), is one of the best-characterized RNA-protein interactions (Fig. 6). This very high affinity complex $\left(K_{D} \sim 30 \mathrm{pM}\right)$ has been examined structurally, biochemically, and kinetically (Scherly et al. 1989, 1990; Lutz-Freyermuth et al. 1990; Hall and Stump 1992; Hall 1994; Oubridge et al. 1994; Kranz and Hall 1998, 1999; Katsamba et al. 2001, 2002a; Law et al. 2005, 2006b; Showalter and Hall 2005). The basis for this tight interaction is an induced fit between regions of the protein and residues 1-7 of the unstructured 10-nucleotide (nt) loop, resulting in an intricate network of RNA-protein contacts (Hall 1994; Oubridge et al. 1994; Kranz and Hall 1998, 1999; Katsamba et al. 2001; Pitici et al. 2002; Law et al. 2006a; Kormos et al. 2007). A high-resolution structure of the U1A-U1hpII complex has been solved (Oubridge et al. 1994), but the structure of the U1hpII RNA alone has not been reported.

In this work, we used LNA substitution to probe the relevance of sugar pucker conformation to RNA-protein binding for two nucleotides, C5 and A6, within the U1hpII terminal loop (Fig. 6). In the co-crystal structure of the complex, residue $\mathrm{C} 5$ took on a $\mathrm{C} 2$ '-endo conformation, whereas A6 was C3'-endo (Oubridge et al. 1994). We introduced LNA individually at C5 and A6 in the form of
TABLE 2. Thermodynamics of UUCG tetraloop RNA analogs

\begin{tabular}{lccccc}
\hline RNA & $\begin{array}{c}\Delta H^{\circ} \\
(\mathrm{kcal} / \mathrm{mol})\end{array}$ & $\begin{array}{c}\Delta S^{\circ} \\
(\mathrm{cal} / \mathrm{mol} \cdot \mathrm{K})\end{array}$ & $\begin{array}{c}\Delta G^{\circ} \\
(\mathrm{kcal} / \mathrm{mol})\end{array}$ & $\begin{array}{c}\Delta G_{55}^{\circ} \\
(\mathrm{kcal} / \mathrm{mol})\end{array}$ & $\begin{array}{c}T_{m} \\
\left({ }^{\circ} \mathrm{C}\right)\end{array}$ \\
\hline UUCG (wt) & $-43.5 \pm 2.7$ & $-125.5 \pm 7.9$ & $-4.6 \pm 0.3$ & $-2.3 \pm 0.2$ & 73.4 \\
UTCG & $-44.1 \pm 3.1$ & $-127.1 \pm 8.7$ & $-4.7 \pm 0.4$ & $-2.4 \pm 0.2$ & 74.1 \\
U(LNA-T)CG & $-32.0 \pm 2.8$ & $-94.8 \pm 8.6$ & $-2.6 \pm 0.2$ & $-0.9 \pm 0.1$ & 64.5 \\
UUCGm & $-33.9 \pm 2.4$ & $-98.6 \pm 7.3$ & $-3.3 \pm 0.2$ & $-1.5 \pm 0.1$ & 70.3 \\
UUC(LNA-G) & $-41.6 \pm 2.4$ & $-123.3 \pm 7.5$ & $-3.3 \pm 0.2$ & $-1.1 \pm 0.1$ & 64.1 \\
\hline
\end{tabular}




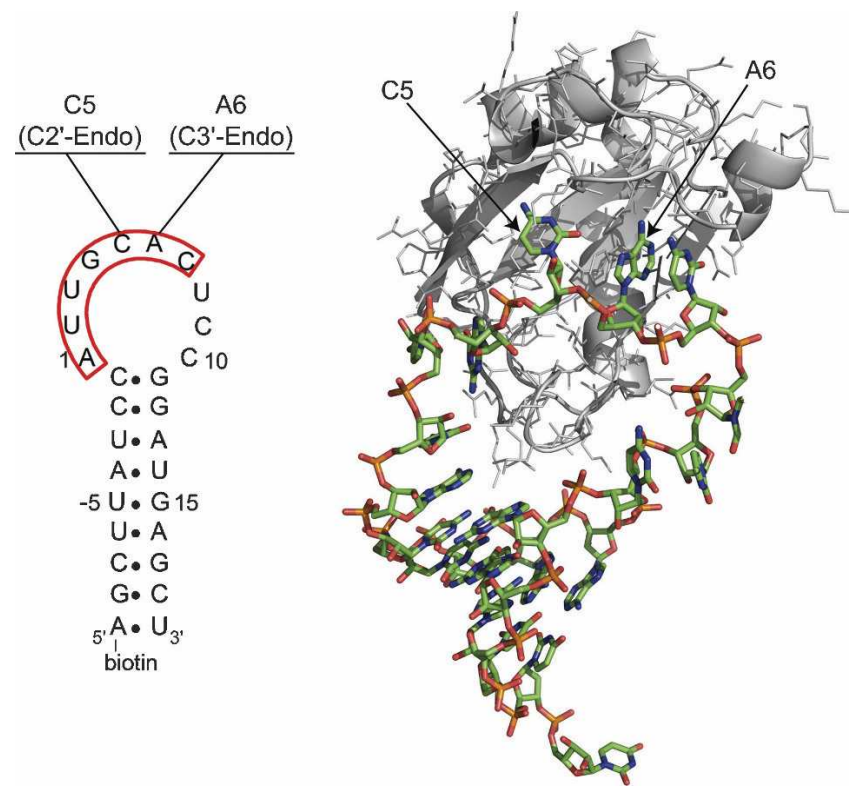

FIGURE 6. Structure of U1 snRNA hairpin II in complex with U1A protein. The secondary structure of the hairpin used for the SPR analysis is shown at left. Nucleotides U-5 to G15 are identical to the wild-type hairpin. The seven highly conserved nucleotides of the terminal loop, which are well structured in the complex, are outlined in red. The two nucleotides probed in this work are indicated along with their sugar pucker phases as observed in the cocrystal structure. (Right) The crystal structure of the protein-RNA complex. The coordinates are taken from Oubridge et al. (1994), pdb code 1URN, with the U1A protein in grayscale. In the numbering convention used, C5 and A6 are the fifth and sixth nucleotides of the 10-nt RNA terminal loop, corresponding to residues 10 and 11 in the numbering of Oubridge et al. (1994). Drawn with PyMOL (Delano 2002).

LNA- $\mathrm{m}^{5} \mathrm{C} 5$ (LNA-5-methyl cytidine) and LNA-A6, respectively. To control for the effects of the loss of the $2^{\prime}-\mathrm{OH}$ functional group as well as of the additional methyl group on the cytosine base, we compared the results to $\mathrm{m}^{5} \mathrm{dC} 5$ (5-methyl-deoxycytidine) and Am6 (2'-O-methyl adenosine) substituted species, respectively, as well as to the wild-type U1hpII (Katsamba et al. 2001). The effects of these substitutions on protein-RNA recognition were analyzed by surface plasmon resonance (SPR), which allows a simultaneous determination of on and off rates for the complex and the binding equilibrium constant $K_{D}$ (Myszka 1999; Katsamba et al. 2001, 2002b).

We first examined the ability of the U1A N-terminal RRM to bind to wild-type U1hpII, $\mathrm{m}^{5} \mathrm{dC} 5 \mathrm{U} 1 \mathrm{hpII}$, and LNA- $\mathrm{m}^{5} \mathrm{C} 5$ U1hpII (Fig. 7; Table 3). Although the effect of the 5-methyl-dC substitution versus wild type was negligible and not statistically significant, locking the C5 ribose in the $3^{\prime}$-endo conformation was very unfavorable for binding, significantly reducing the association rate as well as increasing the dissociation rate, resulting in an overall loss in affinity of over three orders of magnitude. This result is consistent with the requirement for a $\mathrm{C}^{\prime}$-endo ribose at position $\mathrm{C} 5$ to enable binding. Alternatively, the possibility that the interference with binding arises from an introduced RNA-protein steric clash cannot be fully ruled out with the present data (see Discussion).

Next, we examined the effects on binding of Am6 and LNA-A6 substitutions. The 2'-O-methyl A6 showed no change in binding kinetics or affinity, indicating that the 2 '-hydroxyl hydrogen bond donor at this position is unnecessary for protein recognition. Conformational restriction at position A6 also had very minor effects. LNA-A6 showed statistically significant but small changes in association and dissociation rates, resulting in a very modest (threefold) loss in affinity. In other words, preorganization of this nucleotide into the bound conformation observed in the cocrystal structure does not improve the affinity or kinetics of RNA-protein recognition, despite the expectation that such preorganization might increase affinity by reducing the entropic penalty upon binding (Kool 1997). A formal possibility to explain this effect would be that $\mathrm{C} 2$ '-endo and C 3 '-endo conformations at this position are equally compatible with protein binding, but the tightly structured nature of this region of the cocrystal structure would seem to render such a possibility unlikely. Instead, we propose that nucleotide $\mathrm{A} 6$ is already fully $\mathrm{C}^{\prime}$-endo in the free form of the RNA hairpin. Since SPR data are acquired by using a prestructured hairpin, restriction to the $\mathrm{C}^{3}$-endo conformation using LNA would be expected to be reflected solely in the folding of the isolated hairpin, rather than in the docking process. At this site, therefore, LNA substitution may be seen as a probe of the properties of the free form of the RNA by indicating a preorganization of the wild-type U1hpII hairpin into a C3'-endo conformation at A6 in the unbound state. The minor negative effects of substitution at this site may arise from effects of the LNA on the surrounding RNA structure or from the need for flexibility during the induced fit process.

\section{DISCUSSION}

In this work, we have investigated the utility of conformational restriction of nucleotide sugar pucker using LNAs as a probe of RNA structure and function. The three systems considered represent three distinct types of conformational change: the fluctuation of an inactive ground-state structure of the leadzyme to a low-population active conformation of unknown structure, the unfolding of a well-defined structure in the UUCG tetraloop, and a rearrangement of the U1 snRNA hairpin II from a free conformation of unknown structure and dynamics to a protein-bound form with a known structure. In each of these cases, conformational restriction has allowed a distinct insight into the structure and conformational dynamics of the respective system. At sites U6 of the UUCG tetraloop and C5 of U1hpII, both of which are $\mathrm{C} 2$ '-endo in the available crystal structures, imposition of the $\mathrm{C} 3$ '-endo conformation using LNA causes a drastic decrease in thermodynamic stability 

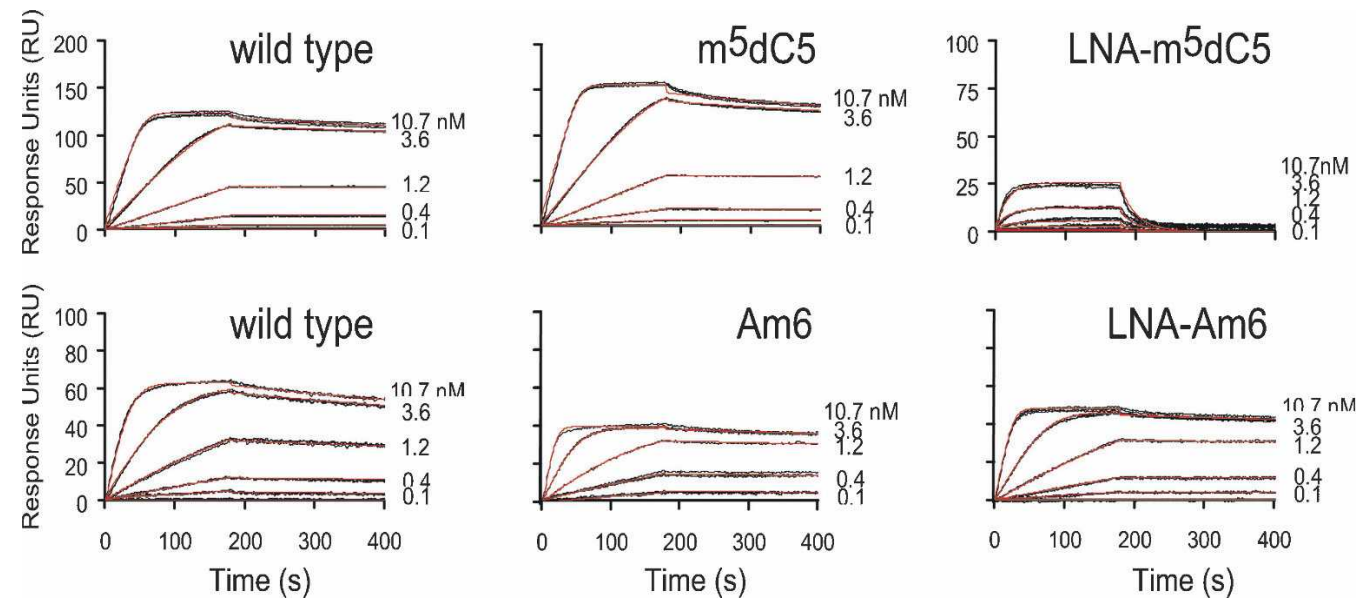

FIGURE 7. Sensorgrams showing kinetic analyses of the U1A N-terminal RRM with U1hpII and mutant RNAs. Protein concentrations injected are as indicated. The scales across each row are consistent, except for the LNA- $\mathrm{m}^{5} \mathrm{C} 5$ plot (upper right) for which the scale was adapted to better show the binding curves of this much weaker interaction. Two different wild-type RNA surfaces were used, to match the surface densities of the C5 and A6 coated RNAs (top and bottom left, respectively). The two wild-type surfaces showed no significant differences in $k_{a}, k_{d}$, or $K_{D}$, and the results from all six wild-type runs were averaged. Black lines represent triplicate injections performed in random order over an indicated RNA surface. A 3-min association was followed by a 5-min dissociation phase. Red lines represent the global fit of data sets using CLAMP (Myszka and Morton 1998). Kinetic parameters obtained from the experiments are given in Table 3.

and protein binding, respectively. These results validate the LNA-substitution method using these well-understood systems and also demonstrate the thermodynamic importance of the observed ribose conformations at these sites. At G7 of the leadzyme and A6 of U1hpII, by contrast, only minor effects are observed, implying that conformational changes at these sites are not critical for the formation of the active state of the leadzyme or for protein recognition by U1hpII. The surprising loss of thermodynamic stability upon LNA substitution at G8 of the UUCG tetraloop, despite the $\mathrm{C}^{\prime}$ structure at this site, may arise from a previously unrecognized structural interaction of the $2^{\prime}$ $\mathrm{OH}$ group, although this requires further investigation. If correct, this analysis suggests a reinterpretation of some previous results in the UUCG system. The results at this site also emphasize the importance of the use of appropriate controls for LNA experiments. Finally, the 20 -fold increase in catalytic rate in the leadzyme upon LNA substitution at G9 provides a precise mapping of a conformational change at this site that appears to be a key part of the generation of the active state of the ribozyme.

For the leadzyme, a pronounced discrepancy between determined structures and chemical and biochemical data has become evident, largely because structural studies, whether NMR or crystallographic, generally report on the most populated (ground-state) form of the molecule (ES). In contrast, the gain or loss of function upon mutation or base substitution reflects the structural requirements of the active conformation, ES* (cf. Fig. 2). Thus, an understanding of this ribozyme's catalytic mechanism and metal-ion specificity requires a knowledge of the features of the ES* state. The results in this article move this effort forward by demonstrating that the ribose ring of G9, and possibly also of G24, invert pseudorotation phase upon activation.

Using mutagenesis and base-substitution data as input for the modeling program MC-SYM (Major et al. 1991; Gautheret et al. 1993), Lemieux et al. (1998) derived a structural model for the leadzyme that, since it is based on

TABLE 3. Kinetic values for the interaction of U1A RRM1 with wild-type, $2^{\prime}$-modified, and LNA RNAs

\begin{tabular}{lcccccc}
\hline RNA target & $\begin{array}{c}k_{a} \\
\left(\mathrm{M}^{-1} \mathrm{sec}^{-1}\right)\end{array}$ & $\begin{array}{c}\text { Fold slower } \\
(\mathrm{wt} / \mathrm{mut})\end{array}$ & $\begin{array}{c}k_{d} \\
\left(\mathrm{sec}^{-1}\right)\end{array}$ & $\begin{array}{c}\text { Fold faster } \\
(\mathrm{mut} / \mathrm{wt})\end{array}$ & $\begin{array}{c}\text { Fold weaker } \\
(\mathrm{mut} / \mathrm{wt})\end{array}$ \\
\hline U1hpll wt & $(1.5 \pm 0.1) \times 10^{7}$ & 1 & $(4.2 \pm 0.5) \times 10^{-4}$ & 1 & $(2.9 \pm 0.4) \times 10^{-11}$ \\
$\mathrm{~m}^{5} \mathrm{dC5}$ & $(1.45 \pm 0.07) \times 10^{7}$ & 1 & $(7 \pm 2) \times 10^{-4}$ & 2 & $(5 \pm 1) \times 10^{-11}$ & 1 \\
LNA-m $^{5} \mathrm{C} 5$ & $(1.1 \pm 0.5) \times 10^{6}$ & $13^{\mathrm{a}}$ & $(5.8 \pm 0.2) \times 10^{-2}$ & $140^{\mathrm{a}}$ & $(9 \pm 4) \times 10^{-8}$ & 3000 \\
Am6 & $(1.1 \pm 0.2) \times 10^{7}$ & 1 & $(3.1 \pm 0.1) \times 10^{-4}$ & 1 & $(3.1 \pm 0.6) \times 10^{-11}$ & 1 \\
LNA-A6 & $(7 \pm 1) \times 10^{6}$ & $2^{\mathrm{a}}$ & $(5.8 \pm 0.2) \times 10^{-4}$ & $1.4^{\mathrm{a}}$ & $(10 \pm 2) \times 10^{-11}$ & $3^{\mathrm{a}}$ \\
\hline
\end{tabular}

${ }^{a}$ Both the C5 LNA and the A6 LNA showed statistically significant changes $(t$-test $P<0.05)$ in the association and dissociation rates compared to the wild-type RNA. In the case of C5 LNA, these changes were considerable, resulting in an over three orders of magnitude loss in affinity. In the case of A6 LNA these changes were statistically significant but minor, resulting in a threefold loss in affinity. 
functional data, may well resemble the active conformation in many respects (Lemieux et al. coordinates are available at http://www-lbit.iro.umontreal.ca/structures/leadzyme.pdb). The potential relevance of this model is supported by its ability to correctly predict the results of three distinct $8 \mathrm{BrG}$ substitutions, a feat accomplished by neither the NMR nor crystallographic ground-state structures (Yajima et al. 2007). The MC-SYM model further contains a C3'-endo ribose at position G9, consistent with the LNA substitution results reported above. Correlations of NMR spin-relaxation studies with biochemical data have also allowed insight, suggesting that the A25-C6 protonated base pair observed in the NMR structure is broken in $\mathrm{ES}^{*}$ (Hoogstraten et al. 2000 ), and crystallographic analysis under varying metalion conditions has begun to reveal the conformational requirements for in-line attack (Wedekind and McKay 1999, 2003). Nevertheless, additional probes are of great interest in order to further constrain the active conformation. Bevilacqua and coworkers took a major step in this direction by using $8 \mathrm{BrG}$ substitutions to perturb the glycosidic angle (Proctor et al. 2003, 2004; Yajima et al. 2007). In this work, we use LNA substitution in a similar fashion to probe the functional relevance of various pucker modes of the ribose moiety. The remarkable 20 -fold increase in catalytic rate upon forcing G9 away from its observed ground-state conformation strongly supports both a C3'-endo conformation in $\mathrm{ES}^{*}$ and an opposing $\mathrm{C}^{\prime}$-endo structure in ES, consistent with both crystallographic and NMR J-coupling analyses. Interestingly, $8 \mathrm{BrG}$ substitution at G24 gave $k_{\mathrm{obs}}$ values of up to $\sim 9 \min ^{-1}$ at $\mathrm{pH} 6$ and elevated $\mathrm{Pb}^{2+}$ concentrations, which would extrapolate to the approximate $k_{\text {obs }}$ of LNA-G9 at pH 7 assuming log-linear dependence of rate on $\mathrm{pH}$. Whether this implies that the two substitutions shift the equilibrium between ES and ES* to the same extent or in the same structural manner is a matter for future investigation. We suggest that the incorporation of data including $8 \mathrm{BrG}$ and LNA substitutions could enhance the accuracy and relevance of computational models of the active state of the leadzyme, as well as providing novel insight into other and possibly less well understood ribozymes.

LNA nucleotides have previously been incorporated into helical regions and/or recognition arms of the 10-23 catalytic DNA and the hammerhead ribozyme in an attempt to improve the targeting of cellular and viral RNA sequences, resulting in sometimes dramatic effects upon structural stability and target affinity (Vester et al. 2002; Christiansen et al. 2007; Donini et al. 2007). The purpose of the LNAribozyme substitutions reported here is quite different, as we intend to probe the catalytic mechanism rather than to enhance hybridization affinity. Thus, the two techniques employing LNA substitutions with catalytic nucleic acids, namely, insertions within double-helical regions for biotechnology and related applications and substitutions within nonhelical regions as a mechanistic probe, are fully complementary.
With any mutation or modification, the primary limitation is the possibility of functional effects arising from features of the probe other than the intended perturbation. In the case of LNAs, this possibility arises either due to the loss of hydrogen-bonding groups on the 2 '-hydroxyl or to the steric bulk of the bridging methylene group. A partial control for these effects is the parallel analysis of $2^{\prime}$-deoxy and/or 2'-O-methyl modifications, as demonstrated in this work by the case of G8 in the UUCG tetraloop. In cases for which either of these modifications is poorly tolerated, the usefulness of LNA probing is reduced. In the ideal case, it would be possible to perform a complementary experiment by locking the ribose into the $\mathrm{C} 2$ '-endo conformation. Such data would allow a more unambiguous interpretation of loss-of-function effects from one or the other variant, as for site C5 of U1hpII in the present study. Nucleosides of various forms that accomplish this have been synthesized (Choi et al. 2003; Maier et al. 2004), but are not yet generally available.

To sum up, the ability to conformationally lock individual nucleotides is a useful addition to the arsenal of techniques for probing the nature and importance of structural and dynamic features in RNA systems. In this article, we have demonstrated insights in cases including ribozyme catalysis, folding thermodynamics, and RNA-protein recognition, including a 20 -fold increase in leadzyme catalysis upon a single modification that provides a strong constraint on conformational aspects of the catalytic mechanism. We have used well-understood systems in order to validate the method by comparison to existing structures and other data, but we believe that the approach may also be very useful in newer systems with less existing information.

\section{MATERIALS AND METHODS}

\section{Reagents and RNA synthesis}

Unless otherwise noted, all chemicals were purchased from SigmaAldrich at the highest purity available. Urea and EDTA were from Invitrogen, acrylamide, bis-acrylamide, and yeast tRNA were from Roche, acetylated bovine serum albumin was from New England Biolabs, surfactant P20 was from GE Healthcare, and boric acid was from Bio-Rad. All LNA phosphoramidites used in RNA synthesis were from Glen Research.

The 30-nt lead-dependent ribozymes were chemically synthesized with a 6-fluorescein tag at the $5^{\prime}$ end. Wild-type oligonucleotides from Dharmacon, Inc. were deprotected according to the manufacturer's protocol. LNA-leadzyme constructs synthesized by the W.M. Keck Foundation Biotechnology Resource laboratory at Yale University were deprotected using tetrabutylammonium fluoride (TBAF) solution in tetrahydrofuran (THF), $6 \mathrm{~h}$ at room temperature. UUCG tetraloop RNA analogs and 5' -biotin labeled U1 snRNA analogs were obtained from the W. M. Keck Facility and deprotected as above. Oligomer sequences, along with their shorthand representations, are as follows: 
Julien et al.

Leadzyme ( $L Z 2)$

wt

LNA-G7

LNA-G9

LNA-G24

\section{UUCG tetraloop}

UUCG

UTCG

U(LNA-T)CG

UUCGm

UUC(LNA-G)

U1 snRNA hairpin II (U1hpll) wt

$\mathrm{m}^{5} \mathrm{dC} 5$

LNA-m ${ }^{5} \mathrm{C} 5$

Am6

LNA-A6
5'-Fl-GCGACCG $7 \mathrm{AG}_{9}$ CCAGCGAAAGUUGG $\mathrm{G}_{24} \mathrm{AGUCGC-3^{ \prime }}$

5'-FI-GCGACC(LNA-G) ${ }_{7}$ AGCCAGCGAAAGU UGGGAGUCGC-3'

5' -FI-GCGACCGA(LNA-G) ${ }_{9}$ CCAGCGAAAGU UGGGAGUCGC-3'

5'-FI-GCGACCGAGCCAGCGAAAGUUG G(LNA-G) ${ }_{24}$ AGUCGC-3'

\author{
5'-GGACUU ${ }_{6} \mathrm{CG}_{8}$ GUCC-3'

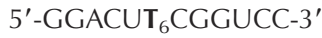 \\ 5'-GGACU (LNA-T) ${ }_{6}$ CGGUCC-3' \\ 5'-GGACUUCGm ${ }_{8}$ GUCC-3' \\ 5'-GGACUUC(LNA-G) ${ }_{8}$ GUCC-3'
}

(BioRad). Bands showing significant pixel saturation were removed from the analysis. Values for substrate and product bands were corrected for background and reported as percent of substrate remaining, $[\mathrm{S}] /([\mathrm{S}]+[\mathrm{P}])$. Reactions proceeded to $>90 \%$ completion in all cases. Time points representing the average of two runs were fit to a single exponential $\left(y_{0}+\mathrm{A}{ }^{*} \mathrm{e}^{-k x}\right)$ using Igor Pro $5.04 \mathrm{~B}$ to yield reported $k_{\text {obs }}$ values. Error estimates for rate determinations were generated from the covariance matrices as reported by the fitting software.

\section{Ultraviolet melting analysis}

The absorbance versus temperature curves of UUCG tetraloop analogs were monitored on a Cary 300 Bio UV/Vis spectrophotometer equipped with an electrothermal temperature controller using 0.1 - and $0.2-\mathrm{cm}$ path length cuvettes (volumes of 350 and $700 \mu \mathrm{L}$, respectively). The buffer used for this experiment contained $10 \mathrm{mM}$ sodium cacodylate and $0.5 \mathrm{mM}$ EDTA ( $\mathrm{pH} 7.0$ ). The total RNA concentration of each sample was determined from the UV absorbance values $(260 \mathrm{~nm})$ at $95^{\circ} \mathrm{C}$ using single-stranded extinction coefficients of $111,600 \mathrm{M}^{-1} \mathrm{~cm}^{-1}$ for UUCG, UUC (LNA-G), and UUCGm, and $94,800 \mathrm{M}^{-1} \mathrm{~cm}^{-1}$ for UTCG and U(LNA-T)CG. These RNA extinction coefficients were calculated using the nearest neighbor algorithm (Cantor and Tinoco 1965) using an extinction coefficient of $12.2 \mathrm{M}^{-1} \mathrm{~cm}^{-1} \times 10^{-3}$ at $\mathrm{pH}$ 7.0 for guanosine, LNA-G, and Gm and $8.7 \mathrm{M}^{-1} \mathrm{~cm}^{-1} \times 10^{-3}$ at pH 7.0 for thymine and LNA-T (Gray et al. 1995). The melting data were collected from $20^{\circ} \mathrm{C}$ to $95^{\circ} \mathrm{C}$ at $280 \mathrm{~nm}$ with a heating rate of $0.5^{\circ} \mathrm{C} / \mathrm{min}$. The thermodynamic parameters were calculated by fitting to a standard two-state model using Meltwin 3.5 (McDowell and Turner 1996). Reported parameters are the average of results at six different RNA concentrations between 5 $\mu \mathrm{M}$ and $100 \mu \mathrm{M}$, each recorded in triplicate.

where LNA indicates a locked nucleic acid with a methylen linkage between $2^{\prime}-O$ and $4^{\prime}-C, \mathrm{Gm}$ is $2^{\prime}$-O-methyl guanosine, Am is $2^{\prime}$-O-methyl adenosine, $\mathrm{m}^{5} \mathrm{dC}$ is $2^{\prime}$-deoxy-5-methyl cytidine, $\mathrm{Fl}$ is fluoroscein, and $\mathrm{Bi}$ is biotin. In some cases, the choice of the particular modification used was dictated by the current availability of the corresponding phosphoramidite. Deprotected RNAs were desalted on Sephadex G-25 (Sigma-Aldrich) and then dialyzed repeatedly against RNAse-free, double-deionized water using Amicon Ultra 15 centrifugal filtration units. Following dialysis, RNAs were analyzed for purity on a $14.5 \%$ denaturing polyacrylamide analytical gel, lyophilized to dryness and stored at $-20^{\circ} \mathrm{C}$.

\section{Leadzyme catalytic assays}

RNA concentrations were determined using a single-stranded extinction coefficient of $2.95 \times 10^{5} \mathrm{M}^{-1} \mathrm{~cm}^{-1}$ at $260 \mathrm{~nm}$ for all variants. Cleavage reactions contained $5 \mu \mathrm{M}$ RNA dialyzed against $15 \mathrm{mM}$ MOPS ( $\mathrm{pH} 7.0$ ) and were performed at $27^{\circ} \mathrm{C} \pm 1{ }^{\circ} \mathrm{C}$. The RNA was renatured by heating to $85^{\circ} \mathrm{C}$ for $2 \mathrm{~min}$ followed by cooling to $22^{\circ} \mathrm{C}$ and incubation at $27^{\circ} \mathrm{C}$ for $15 \mathrm{~min}$. Cleavage reactions were initiated by addition of freshly prepared $\mathrm{Pb}(\mathrm{OAc})_{2}$ at $10 \mu \mathrm{M}, 25 \mu \mathrm{M}, 50 \mu \mathrm{M}, 100 \mu \mathrm{M}, 250 \mu \mathrm{M}$, or $500 \mu \mathrm{M}$. For each time point, $35 \mu \mathrm{L}$ aliquots were removed, quenched in an equal volume of $9 \mathrm{M}$ urea $/ 50 \mathrm{mM}$ EDTA, and stored at $-20^{\circ} \mathrm{C}$. The unreacted substrate and product RNAs were separated on $14.5 \%$ denaturing polyacrylamide gels. Bands were detected with a FluorS MAX Multilmager with excitation at $494 \mathrm{~nm}$ and measurement of emission at $518 \mathrm{~nm}$ and analyzed with Quantity One software

\section{Surface plasmon resonance of RNA-U1A binding}

Binding experiments were performed on a BIACORE 2000 instrument (GE Healthcare) as described with small modifications (Katsamba et al. 2002b; Law et al. 2006b). RNA was diluted to a final concentration of $0.1 \mu \mathrm{M}$ in HBS buffer (10 mM HEPES at $\mathrm{pH} 7.4,150 \mathrm{mM} \mathrm{NaCl}, 3 \mathrm{mM}$ EDTA, 0.005\% surfactant P20) followed by heating at $80^{\circ} \mathrm{C}$ for $10 \mathrm{~min}$ and cooling to room temperature for $60 \mathrm{~min}$ to allow annealing of the stem. The sample was then diluted (50-fold for wild type, $\mathrm{m}^{5} \mathrm{dC} 5$, and LNA$\mathrm{m}^{5} \mathrm{C} 5$ and 1000-fold for Am6 and LNA-A6) in $2 \times$ running buffer to $10 \mathrm{mM}$ Tris/ $\mathrm{HCl}$ (pH 8.0), $150 \mathrm{mM} \mathrm{NaCl}, 5 \%$ glycerol, $125 \mu \mathrm{g}$

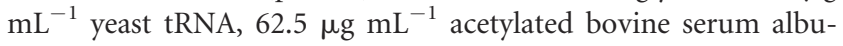
min, $1 \mathrm{mM}$ dithiothreitol, $0.005 \%$ surfactant P20 and injected over a commercial streptavidin-coated sensor chip (SA chip, GE

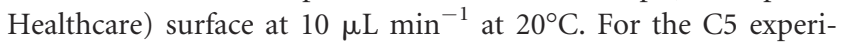
ment, three comparable density surfaces were generated on one chip (wild-type U1hpII, $\mathrm{m}^{5} \mathrm{dC} 5$, LNA- $\mathrm{m}^{5} \mathrm{C} 5$ ), with the fourth flow cell left blank to allow background signal subtraction. A separate chip was generated for the A6 analysis, containing wild-type U1hpII, Am6, LNA-A6, and an unmodified surface. RNA densities (including the wild-type reference channel) coated on the C5 chip were slightly higher than on the A6 surfaces to compensate for the weak binding of C5 LNA. Recombinant, C-terminally hexahistidine-tagged U1A protein (amino acids 1-101) (Law et al. 2006b) 
was serially diluted in running buffer to the concentrations indicated in Figure 7 and injected at $20^{\circ} \mathrm{C}$ at a flow rate of $50 \mu \mathrm{L}$ $\min ^{-1}$ for $3 \mathrm{~min}$ (association phase). Disruption of any complex that remained bound after a 5-min dissociation was achieved using a 1-min injection of $2 \mathrm{M} \mathrm{NaCl}$ at $20 \mu \mathrm{L} \mathrm{min}{ }^{-1}$. Samples with different concentrations of protein were injected in random order, and every injection was performed in triplicate within each experiment. All experiments were done at least three times. To subtract any background noise from each data set, all samples were also run over an unmodified sensor chip surface and random injections of running buffer were performed throughout every experiment ("double referencing") (Myszka 1999). Data were processed using Scrubber and analyzed using CLAMP XP (Myszka and Morton 1998) (developed by the Biomolecular Interaction Facility at the University of Utah, www.cores.utah.edu/interaction). The data were fit globally using a simple 1:1 Langmuir interaction model with a correction for mass transport (Myszka and Morton 1998). The results for all mutants were compared to the wild-type RNA using the Student's $t$-test. Equal or unequal variance of the samples was determined using the F-test. Equilibrium binding constants were calculated for each individual experiment, and these values were used to compute the averages and standard error of the means reported in Table 3.

\section{ACKNOWLEDGMENTS}

The authors are grateful to Olke Uhlenbeck and Philip Bevilacqua for helpful discussions and to Gregory Zeikus and Claire Vieille for the use of the UV-melting apparatus. This research was supported by NIH grant GM069742 to C.G.H. and NSF grant MCB-0131782 to I.A.L.-O.

Received March 5, 2008; accepted April 17, 2008.

\section{REFERENCES}

Altona, C. and Sundaralingam, M. 1972. Conformational analysis of the sugar ring in nucleosides and nucleotides. A new description using the concept of pseudorotation. J. Am. Chem. Soc. 94: 82058212.

Antao, V.P. and Tinoco Jr., I. 1992. Thermodynamic parameters for loop formation in RNA and DNA hairpin tetraloops. Nucleic Acids Res. 20: 819-824.

Boisbouvier, J., Brutscher, B., Pardi, A., Marion, D., and Simorre, J.P. 2000. NMR determination of sugar puckers in nucleic acids from CSA-dipolar cross-correlated relaxation. J. Am. Chem. Soc. 122: 6779-6780.

Braasch, D.A. and Corey, D.R. 2001. Locked nucleic acid (LNA): Fine-tuning the recognition of DNA and RNA. Chem. Biol. 8: $1-7$.

Cantor, C.R. and Tinoco Jr., I. 1965. Absorption and optical rotatory dispersion of seven trinucleoside diphosphates. J. Mol. Biol. 13: 65-77.

Chartrand, P., Usman, N., and Cedergren, R. 1997. Effect of structural modifications on the activity of the leadzyme. Biochemistry 36: 3145-3150.

Cheong, C., Varani, G., and Tinoco Jr., I. 1990. Solution structure of an unusually stable RNA hairpin, 5'GGAC(UUCG)GUCC. Nature 346: $680-682$.

Choi, Y., Moon, H.R., Yoshimura, Y., and Marquez, V.E. 2003. Recent advances in the synthesis of conformationally locked nucleosides and their success in probing the critical question of conformational preferences by their biological targets. Nucleosides Nucleotides Nucleic Acids 22: 547-557.

Christiansen, J.K., Lobedanz, S., Arar, K., Wengel, J., and Vester, B. 2007. LNA nucleotides improve cleavage efficiency of singular and binary hammerhead ribozymes. Bioorg. Med. Chem. 15: 61356143.

Delano, W.L. 2002. The PyMOL molecular graphics system. DeLano Scientific, Palo Alto, CA.

Donini, S., Clerici, M., Wengel, J., Vester, B., and Peracchi, A. 2007. The advantages of being locked. Assessing the cleavage of short and long RNAs by locked nucleic acid-containing 8-17 deoxyribozymes. J. Biol. Chem. 282: 35510-35518.

Ennifar, E., Nikulin, A., Tishchenko, S., Serganov, A., Nevskaya, N., Garber, M., Ehresmann, B., Ehresmann, C., Nikonov, S., and Dumas, P. 2000. The crystal structure of UUCG tetraloop. J. Mol. Biol. 304: 35-42.

Fedor, M.J. and Williamson, J.R. 2005. The catalytic diversity of RNAs. Nat. Rev. Mol. Cell Biol. 6: 399-412.

Gautheret, D., Major, F., and Cedergren, R. 1993. Modeling the threedimensional structure of RNA using discrete nucleotide conformational sets. J. Mol. Biol. 229: 1049-1064.

Gray, D.M., Hung, S.H., and Johnson, K.H. 1995. Absorption and circular dichroism spectroscopy of nucleic acid duplexes and triplexes. Methods Enzymol. 246: 19-34.

Groebe, D.R. and Uhlenbeck, O.C. 1988. Characterization of RNA hairpin loop stability. Nucleic Acids Res. 16: 11725-11735.

Guschlbauer, W. and Jankowski, K. 1980. Nucleoside conformation is determined by the electronegativity of the sugar substituent. Nucleic Acids Res. 8: 1421-1433.

Hall, K.B. 1994. Interaction of RNA hairpins with the human U1A N-terminal RNA binding domain. Biochemistry 33: 1007610088.

Hall, K.B. and Stump, W.T. 1992. Interaction of N-terminal domain of U1A protein with an RNA stem/loop. Nucleic Acids Res. 20: 4283-4290.

Hoogstraten, C.G., Legault, P., and Pardi, A. 1998. NMR solution structure of the lead-dependent ribozyme: Evidence for dynamics in RNA catalysis. J. Mol. Biol. 284: 337-350.

Hoogstraten, C.G., Wank, J.R., and Pardi, A. 2000. Active site dynamics in the lead-dependent ribozyme. Biochemistry 39: 99519958.

Johnson Jr., J.E., Julien, K.R., and Hoogstraten, C.G. 2006. Alternatesite isotopic labeling of ribonucleotides for NMR studies of ribose conformational dynamics in RNA. J. Biomol. NMR 35: 261-274.

Karkare, S. and Bhatnagar, D. 2006. Promising nucleic acid analogs and mimics: Characteristic features and applications of PNA, LNA, and morpholino. Appl. Microbiol. Biotechnol. 71: 575586.

Katsamba, P.S., Myszka, D.G., and Laird-Offringa, I.A. 2001. Two functionally distinct steps mediate high affinity binding of U1A protein to U1 hairpin II RNA. J. Biol. Chem. 276: 2147621481.

Katsamba, P.S., Bayramyan, M., Haworth, I.S., Myszka, D.G., and Laird-Offringa, I.A. 2002a. Complex role of the $\beta 2-\beta 3$ loop in the interaction of U1A with U1 hairpin II RNA. J. Biol. Chem. 277: 33267-33274.

Katsamba, P.S., Park, S., and Laird-Offringa, I.A. 2002b. Kinetic studies of RNA-protein interactions using surface plasmon resonance. Methods 26: 95-104.

Kaur, H., Babu, B.R., and Maiti, S. 2007. Perspectives on chemistry and therapeutic applications of locked nucleic acid (LNA). Chem. Rev. 107: 4672-4697.

Kierzek, E., Ciesielska, A., Pasternak, K., Mathews, D.H., Turner, D.H., and Kierzek, R. 2005. The influence of locked nucleic acid residues on the thermodynamic properties of $2^{\prime}-O$ methyl RNA/RNA heteroduplexes. Nucleic Acids Res. 33: 50825093. 
Kool, E.T. 1997. Preorganization of DNA: Design principles for improving nucleic acid recognition by synthetic oligonucleotides. Chem. Rev. 97: 1473-1488.

Kormos, B.L., Benitex, Y., Baranger, A.M., and Beveridge, D.L. 2007. Affinity and specificity of protein U1A-RNA complex formation based on an additive component free energy model. J. Mol. Biol. 371: 1405-1419.

Koshkin, A.A., Rajwanshi, V.K., and Wengel, J. 1998a. Novel convenient syntheses of LNA [2.2.1]bicyclo nucleosides. Tetrahedron Lett. 39: 4381-4384.

Koshkin, A.A., Singh, S.K., Nielsen, P., Rajwanshi, V.K., Kumar, R., Meldgaard, M., Olsen, C.E., and Wengel, J. 1998b. LNA (locked nucleic acids): Synthesis of the adenine, cytosine, guanine, 5methylcytosine, thymine and uracil bicyclonucleoside monomers, oligomerization, and unprecedented nucleic acid recognition. Tetrahedron 54: 3607-3630.

Kranz, J.K. and Hall, K.B. 1998. RNA binding mediates the local cooperativity between the $\beta$-sheet and the C-terminal tail of the human U1A RBD1 protein. J. Mol. Biol. 275: 465-481.

Kranz, J.K. and Hall, K.B. 1999. RNA recognition by the human U1A protein is mediated by a network of local cooperative interactions that create the optimal binding surface. J. Mol. Biol. 285: 215-231.

Law, M.J., Chambers, E.J., Katsamba, P.S., Haworth, I.S., and LairdOffringa, I.A. 2005. Kinetic analysis of the role of the tyrosine 13, phenylalanine 56 and glutamine 54 network in the U1A/U1 hairpin II interaction. Nucleic Acids Res. 33: 2917-2928.

Law, M.J., Linde, M.E., Chambers, E.J., Oubridge, C., Katsamba, P.S., Nilsson, L., Haworth, I.S., and Laird-Offringa, I.A. 2006a. The role of positively charged amino acids and electrostatic interactions in the complex of U1A protein and U1 hairpin II RNA. Nucleic Acids Res. 34: 275-285.

Law, M.J., Rice, A.J., Lin, P., and Laird-Offringa, I.A. 2006b. The role of RNA structure in the interaction of U1A protein with U1 hairpin II RNA. RNA 12: 1168-1178.

Legault, P., Hoogstraten, C.G., Metlitzky, E., and Pardi, A. 1998. Order, dynamics, and metal binding in the lead-dependent ribozyme. J. Mol. Biol. 284: 325-335.

Lemieux, S., Chartrand, P., Cedergren, R., and Major, F. 1998. Modeling active RNA structures using the intersection of conformational space: Application to the lead-activated ribozyme. RNA 4: 739-749.

Lutz-Freyermuth, C., Query, C.C., and Keene, J.D. 1990. Quantitative determination that one of two potential RNA-binding domains of the A protein component of the U1 small nuclear ribonucleoprotein complex binds with high affinity to stem-loop II of U1 RNA. Proc. Natl. Acad. Sci. 87: 6393-6397.

Ma, H., Proctor, D.J., Kierzek, E., Kierzek, R., Bevilacqua, P.C., and Gruebele, M. 2006. Exploring the energy landscape of a small RNA hairpin. J. Am. Chem. Soc. 128: 1523-1530.

Maier, M.A., Choi, Y., Gaus, H., Barchi Jr., J.J., Marquez, V.E., and Manoharan, M. 2004. Synthesis and characterization of oligonucleotides containing conformationally constrained bicyclo [3.1.0] hexane pseudosugar analogs. Nucleic Acids Res. 32: 36423650.

Major, F., Turcotte, M., Gautheret, D., Lapalme, G., Fillion, E., and Cedergren, R. 1991. The combination of symbolic and numerical computation for three-dimensional modeling of RNA. Science 253: $1255-1260$.

McDowell, J.A. and Turner, D.H. 1996. Investigation of the structural basis for thermodynamic stabilities of tandem GU mismatches: Solution structure of (rGAGGUCUC) 2 by two-dimensional NMR and simulated annealing. Biochemistry 35: 14077-14089.

Miller, J.L. and Kollman, P.A. 1997. Theoretical studies of an exceptionally stable RNA tetraloop: Observation of convergence from an incorrect NMR structure to the correct one using unrestrained molecular dynamics. J. Mol. Biol. 270: 436-450.

Myszka, D.G. 1999. Improving biosensor analysis. J. Mol. Recognit. 12: 279-284.
Myszka, D.G. and Morton, T.A. 1998. CLAMP: A biosensor kinetic data analysis program. Trends Biochem. Sci. 23: 149150

Obika, S., Nanbu, D., Hari, Y., Andoh, J., Morio, K., Doi, T., and Imanishi, T. 1998. Stability and structural features of the duplexes containing nucleoside analogues with a fixed N-type conformation, 2'-O,4'-C-methyleneribonucleosides. Tetrahedron Lett. 39: 5401-5404.

Oubridge, C., Ito, N., Evans, P.R., Teo, C.H., and Nagai, K. 1994. Crystal structure at 1.92 A resolution of the RNA-binding domain of the U1A spliceosomal protein complexed with an RNA hairpin. Nature 372: 432-438.

Pan, T. and Uhlenbeck, O.C. 1992. A small metalloribozyme with a two-step mechanism. Nature 358: 560-563.

Pan, T., Dichtl, B., and Uhlenbeck, O.C. 1994. Properties of an in vitro selected $\mathrm{Pb}^{2+}$ cleavage motif. Biochemistry 33: 95619565.

Perez-Canadillas, J.M. and Varani, G. 2001. Recent advances in RNAprotein recognition. Curr. Opin. Struct. Biol. 11: 53-58.

Pitici, F., Beveridge, D.L., and Baranger, A.M. 2002. Molecular dynamics simulation studies of induced fit and conformational capture in U1A-RNA binding: Do molecular substates code for specificity? Biopolymers 65: 424-435.

Proctor, D.J., Kierzek, E., Kierzek, R., and Bevilacqua, P.C. 2003. Restricting the conformational heterogeneity of RNA by specific incorporation of 8-bromoguanosine. J. Am. Chem. Soc. 125: 23902391.

Proctor, D.J., Ma, H., Kierzek, E., Kierzek, R., Gruebele, M., and Bevilacqua, P.C. 2004. Folding thermodynamics and kinetics of YNMG RNA hairpins: Specific incorporation of 8-bromoguanosine leads to stabilization by enhancement of the folding rate. Biochemistry 43: 14004-14014.

Saenger, W. 1984. Principles of nucleic acid structure. Springer, New York.

Sakata, T., Hiroaki, H., Oda, Y., Tanaka, T., Ikehara, M., and Uesugi, S. 1990. Studies on the structure and stabilizing factor of the CUUCGG hairpin RNA using chemically synthesized oligonucleotides. Nucleic Acids Res. 18: 3831-3839.

Scherly, D., Boelens, W., van Venrooij, W.J., Dathan, N.A., Hamm, J., and Mattaj, I.W. 1989. Identification of the RNA binding segment of human U1A protein and definition of its binding site on U1 snRNA. EMBO J. 8: 4163-4170.

Scherly, D., Boelens, W., Dathan, N.A., van Venrooij, W.J., and Mattaj, I.W. 1990. Major determinants of the specificity of interaction between small nuclear ribonucleoproteins U1A and U2B" and their cognate RNAs. Nature 345: 502-506.

Showalter, S.A. and Hall, K.B. 2005. Correlated motions in the U1 snRNA stem/loop 2:U1A RBD1 complex. Biophys. J. 89: 20462058.

Treiber, D.K. and Williamson, J.R. 2001. Beyond kinetic traps in RNA folding. Curr. Opin. Struct. Biol. 11: 309-314.

Tuerk, C., Gauss, P., Thermes, C., Groebe, D.R., Gayle, M., Guild, N., Stormo, G., d'Aubenton-Carafa, Y., Uhlenbeck, O.C., Tinoco Jr., I., et al. 1988. CUUCGG hairpins: Extraordinarily stable RNA secondary structures associated with various biochemical processes. Proc. Natl. Acad. Sci. 85: 1364-1368.

Uesugi, S., Miki, H., Ikehara, M., Iwahashi, H., and Kyogoku, Y. 1979. A linear relationship between electronegativity of $2^{\prime}$-substituents and conformation of adenine nucleosides. Tetrahedron Lett. 20: 4073-4076.

Varani, G., Cheong, C., and Tinoco Jr., I. 1991. Structure of an unusually stable RNA hairpin. Biochemistry 30: 3280-3289.

Vester, B. and Wengel, J. 2004. LNA (locked nucleic acid): Highaffinity targeting of complementary RNA and DNA. Biochemistry 43: 13233-13241.

Vester, B., Lundberg, L.B., Sorensen, M.D., Babu, B.R., Douthwaite, S., and Wengel, J. 2002. LNAzymes: Incorporation of LNA-type monomers into DNAzymes markedly increases RNA cleavage. J. Am. Chem. Soc. 124: 13682-13683. 
Wedekind, J.E. and McKay, D.B. 1999. Crystal structure of a leaddependent ribozyme revealing metal binding sites relevant to catalysis. Nat. Struct. Biol. 6: 261-268.

Wedekind, J.E. and McKay, D.B. 2003. Crystal structure of the leadzyme at $1.8 \AA$ resolution: Metal ion binding and the implications for catalytic mechanism and allo site ion regulation. Biochemistry 42: 9554-9563.

Williams, D.J. and Hall, K.B. 1999. Unrestrained stochastic dynamics simulations of the UUCG tetraloop using an implicit solvation model. Biophys. J. 76: 3192-3205.
Williams, D.J. and Hall, K.B. 2000. Experimental and theoretical studies of the effects of deoxyribose substitutions on the stability of the UUCG tetraloop. J. Mol. Biol. 297: 251-265.

Williams, D.J., Boots, J.L., and Hall, K.B. 2001. Thermodynamics of $2^{\prime}$-ribose substitutions in UUCG tetraloops. RNA 7: 44-53.

Yajima, R., Proctor, D.J., Kierzek, R., Kierzek, E., and Bevilacqua, P.C. 2007. A conformationally restricted guanosine analog reveals the catalytic relevance of three structures of an RNA enzyme. Chem. Biol. 14: 23-30. 

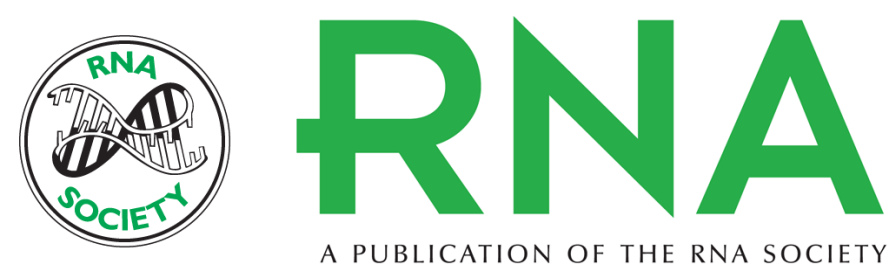

A PUBLICATION OF THE RNA SOCIETY

\section{Conformationally restricted nucleotides as a probe of structure- function relationships in RNA}

Kristine R. Julien, Minako Sumita, Po-Han Chen, et al.

RNA 2008 14: 1632-1643

References This article cites 70 articles, 9 of which can be accessed free at:

http://rnajournal.cshlp.org/content/14/8/1632.full.html\#ref-list-1

License

Email Alerting Receive free email alerts when new articles cite this article - sign up in the box at the Service top right corner of the article or click here. 